\title{
Pore pressure coefficient in frozen soils
}

\author{
CHUANGXIN LYU*, GUSTAV GRIMSTAD $\dagger$ and SATOSHI NISHIMURA $\ddagger$
}

\begin{abstract}
The Skempton pore pressure coefficient, $B$, is defined as the variation in pore pressure with the unit change in confining pressure under undrained conditions. The $B$ parameter is an essential parameter to consider the coupled effects of solid-fluid compressibility and skeleton compressibility in a porous system. It is a key factor in exploring a possible definition of effective stress in frozen soil. However, limited experimental and theoretical research is available in the literature to give insight to the problem. Therefore, a series of $B$ tests on frozen clay was conducted in this study. Results from these tests, along with tests on Ottawa sand, as available in the literature, are analysed considering the effect of the ice crystallisation mode on the skeleton stiffness. The measured $B$ values were lower than expected compared with $B$ values using models that consider single grain bulk stiffness. However, when the difference in bulk stiffness of ice and that of soil grains is considered, even an increase in pore volume, for an increase in fluid pressure, at constant Terzaghi effective stress is possible. The 'pore stiffness', which is different from the solid phase stiffness, can take a negative value and can be used to explain the low measured $B$ values.
\end{abstract}

KEYWORDS: compressibility; ground freezing; temperature effects

\section{INTRODUCTION}

Frozen saturated soils generally consist of solid minerals, ice and water. This poses a question: what is a good effective stress measure for frozen soils? This question reflects the difference in stiffness between water and ice and the influence on how the ice forms in the soil - that is, mainly in the centre of the pores or on the surface of the grains indicated as the typical microstructure of frozen saturated soil in Fig. 1(a). For investigating a relevant effective stress measure, the Skempton pore pressure coefficient, $B$, defined as the variation in pore pressure $u$ with the unit change in confining pressure $p$ under undrained condition (Skempton, 1954), is essential

$$
B=\left(\frac{\partial u}{\partial p}\right)_{\text {undrained }}
$$

As one of the parameters in Biot theory (Berryman \& Milton, 1991; Berryman, 1992), the $B$ value plays an important role in many aspects of permafrost or frozen soil behaviour. It is essential for estimating seismic compressional wave velocity (Dou et al., 2017), thermo-hydro-mechanical behaviours (Ghoreishian Amiri et al., 2016) and permafrost landslide risk (Dramis et al., 1995; Patton et al., 2019). There is a limited number of studies available in the literature on $B$ value measurements and relevant theoretical studies for

Manuscript received 9 May 2021; revised manuscript accepted 4 August 2021.

Discussion on this paper is welcomed by the editor.

Published with permission by the ICE under the CC-BY 4.0 license. (http://creativecommons.org/licenses/by/4.0/)

* Department of Civil and Environmental Engineering, Norwegian University of Science and Technology (NTNU), Trondheim, Norway (Orcid:0000-0003-2794-1890).

$\dagger$ Department of Civil and Environmental Engineering, Norwegian University of Science and Technology (NTNU), Trondheim, Norway (Orcid:0000-0003-4433-2659).

t Division of Civil Engineering, Faculty of Engineering, Hokkaido

University, Hokkaido, Japan. frozen soils. However, some measurements and theoretical developments have been carried out for unfrozen soils and rocks (Hart \& Wang, 2010; Makhnenko \& Labuz, 2016). To the present authors' knowledge, only Kia (2012) has addressed $B$ value measurement for frozen saline sand, with significant effort. A key reason is the challenge in keeping a hydraulic connectivity between the unfrozen water phase in the sample and the pore pressure sensor. A common standard for pore pressure measurement of frozen soils has not been established. Another reason is the requirement to apply a relatively limited range of hydraulic pressure for the $B$ value measurement of frozen soils. Frozen soil in geotechnical and permafrost engineering is typically subject to a low stress range (order of $100 \mathrm{kPa}$ ), unlike in rock engineering, where much higher stress levels are involved (up to the order of MPa or even tens of MPa), for example as encountered in mountain tunnels and mine shafts. Besides, a high overall stress level can be further magnified at local grain-to-grain/ice contacts, and result in significant ice melting and further changes in the soil skeleton for frozen soils. As a result, relatively low pressure (up to $100 \mathrm{kPa}$ ) is favoured to ensure that the unfrozen water content and skeleton remain roughly unchanged.

In order to study the $B$ value of frozen soils both experimentally and theoretically, the present work firstly followed the pore pressure measurement proposed by Arenson \& Springman (2005), who conducted $B$ value measurement in a specially designed triaxial cell similar to that shown in Fig. 2. P-wave velocity for frozen Onsøy clay was measured using the experimental method suggested by Yun et al. (2007) in order to estimate the unfrozen water saturation (UWS) defined as $S_{\mathrm{w}}=V_{\mathrm{w}} /\left(V_{\mathrm{w}}+V_{\mathrm{i}}\right)$ in Fig. 1(b) and the skeleton stiffness. Regarding the theoretical analysis of $B$ value, this study adopted three effective medium theories: namely, the modified Kuster and Toksöz's model (KT model) (Kuster \& Toksöz, 1974; Zimmerman \& King, 1986), matrix cementing (Ecker et al., 1998) and grain coating (Dvorkin et al., 1999) to estimate the change in $B$ value with decrease in the UWS based on different ice crystallisation modes. The paper finally discusses the effect of pore bulk modulus and loading history on the $B$ value of frozen soils. 


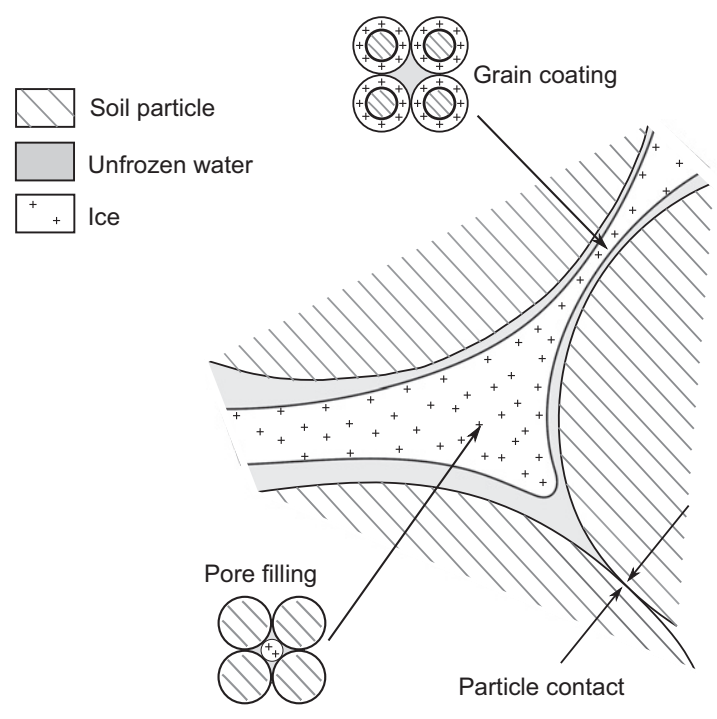

(a)

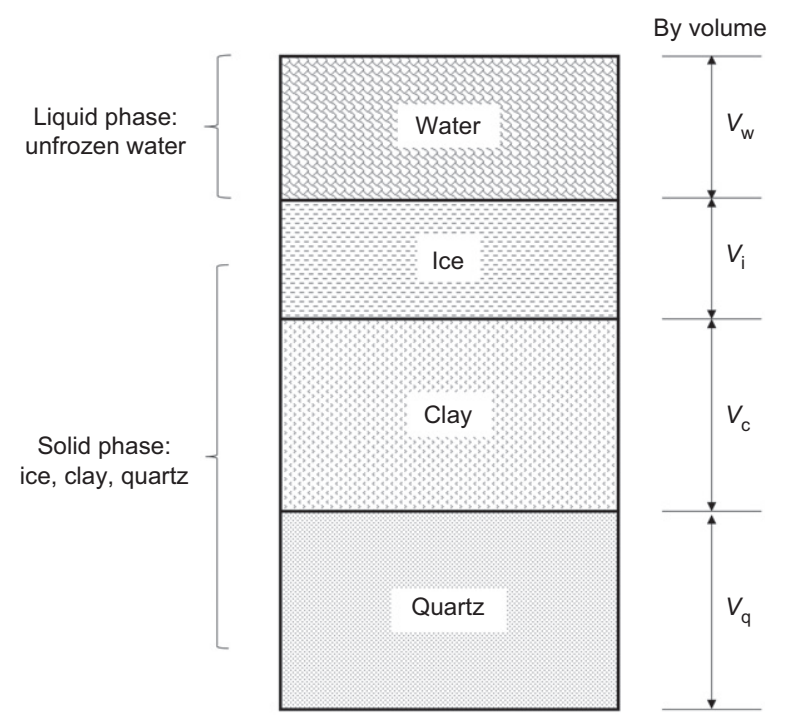

(b)

Fig. 1. (a) Typical microstructure of frozen saturated soil. (b) Schematic phase diagram

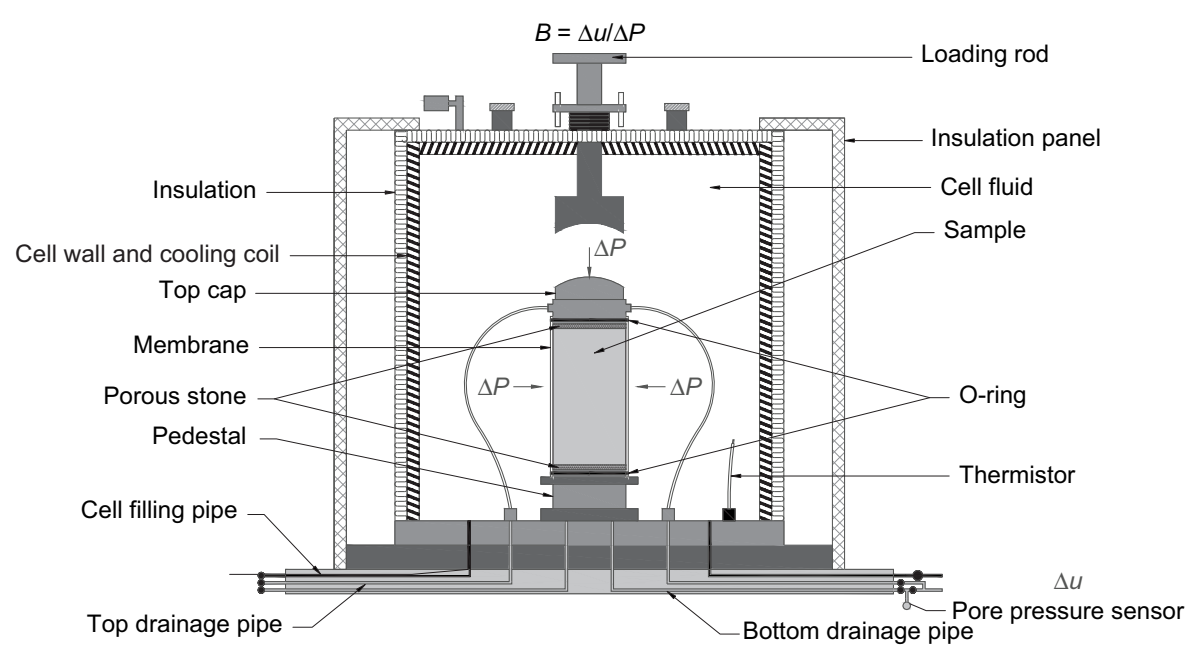

(a)

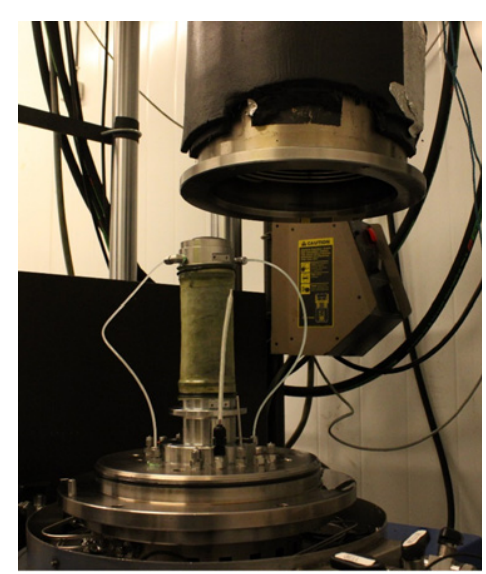

(b)

Fig. 2. (a) Triaxial apparatus sketch. (b) Set-up of specimen. (Note: the actual scale is not followed in Fig. 2(a). The thermocouple is $3 \mathrm{~cm}$ away from sample and located at the mid-height of the sample)

\section{MEASUREMENT AND EXPERIMENTAL RESULTS Pore pressure coefficient measurement}

Onsøy clay, which is found in south-eastern Norway near Fredrikstad, has been the subject of research for 50 years by the Norwegian Geotechnical Institute (NGI) (Oslo, Norway) and others, and has recently been chosen as one of five Norwegian geotest sites (NGTs) (Gundersen et al., 2019). It is homogeneous, fully saturated, soft marine clay with typical salinity $20-30 \mathrm{~g} / 1$ and water content $50-70 \%$. The soil is slightly overconsolidated and contains a significant amount of glacial rock flour, clay minerals (mostly illite and chlorite), quartz and feldspars, with typically $50 \%$ clay and $50 \%$ silt content. The plasticity limit and liquid limit are of the order $20 \%$ and $60 \%$, respectively, and the permeability coefficient at in situ effective stress is $10^{-9} \mathrm{~m} / \mathrm{s}$.

Natural Onsøy clay was used to prepare artificial frozen samples with a 'slow' freezing method, which minimises the thermal gradient and further induced water redistribution during freezing. A cylindrical soil sample $150 \mathrm{~mm}$ long and $74 \mathrm{~mm}$ in diameter was sealed and immersed inside anti-freezing liquid in a container with much larger volume
(12 1). The sample and container were placed inside a low-freezing-rate fridge. The temperature was lowered down to $1^{\circ} \mathrm{C}$ from room temperature until the whole system reached thermal equilibrium. Further freezing continued down to the testing temperatures $\left(-3,-5\right.$ and $-10^{\circ} \mathrm{C}$ in this study). The whole freezing process took at least $48 \mathrm{~h}$. A triaxial set-up (shown in Fig. 2) was developed with precise temperature control and the capability of $B$ value measurement. The apparatus allowed both constant strain rate and constant stress loading. The feedback temperature control was achieved by continuously adjusting the temperature of circulating fluid through a spiral copper coil inside the cell to maintain the temperature, as measured by a thermocouple $30 \mathrm{~mm}$ away from the sample, equal to the testing temperature.

Particular care is necessary for $B$ value measurement in frozen soils. It is achieved by ensuring a low system compressibility and minimum amount of extra fluid volume by adopting both rigid pore pressure sensors and short high-pressure stainless steel tubing (Bishop, 1976; Mesri et al., 1976; Makhnenko \& Labuz, 2016). The pressure 
connectivity between the unfrozen water phase and the pore pressure sensor requires flow path connectivity and fluid phase continuity inside frozen soil. This study adopted anti-freeze liquid (a mixture of ethylene glycol and water) to keep the drainage system (including porous stone and pipelines) unfrozen for flow path connectivity in the subzero temperature. The ethylene glycol concentration should be relatively low to minimise any thawing effect on frozen soils. In clay the water phase can become discontinuous with the degree of saturation below 30-40\% (Romero et al., 1999; Romero \& Simms, 2008). Pore pressure measurement for $T=-10^{\circ} \mathrm{C}$ testing might not secure fluid phase continuity and could result in measurements that are only representative of locality. The system saturation should also be maintained, although it is quite difficult to check this. The $B$ value of unfrozen Onsøy clay, tested at the same triaxial set-up, is equal to 0.98 with $0-100 \mathrm{kPa}$ back-pressure. This indirectly suggests that the natural soil was fully saturated, and proper pipeline flushing and 'low' back-pressure can de-air the system properly. X-ray scanning was also conducted and potentially freezing-induced air bubbles or voids were not found. Besides $300 \mathrm{kPa}$ cell pressure and $50-100 \mathrm{kPa}$ backpressure were applied to the post-freezing consolidation to secure the pore pressure equilibrium before the $B$ test. In the $B$ tests, $p$ was increased by $\Delta p=20 \mathrm{kPa}$ in each step until a maximum value of $400 \mathrm{kPa}$. Fig. 3 shows the $u$ plotted against $p$ response marked as 'pre-loading' for natural Onsøy clay with different salinity and temperature values. The cell pressure was reduced back to $300 \mathrm{kPa}$ following the same path (no hysteresis observed). Next, a 1\%/h constant strain rate loading test was conducted in the undrained condition until $20 \%$ vertical strain was reached. After the constant strain rate loading test, the load was gradually relaxed to zero. Furthermore, the pore pressure reached equilibrium again. In order to test possible $B$ value changes due to the loading test, the same $B$ test procedure was followed again and termed the post-loading-unloading $B$ value measurement (results marked as 'post-loading' in Fig. 3). The $B$ value results show a significant increase after loading-unloading and decrease with the decrease of temperature $\left(-3\right.$ to $\left.-10^{\circ} \mathrm{C}\right)$ and salinity (no. 2, $30 \mathrm{~g} / \mathrm{l}$ as opposed to no. 3, $20 \mathrm{~g} / \mathrm{l}$ ).

\section{Measurement of P-wave velocity and estimate of $U W S$}

In this study, P-wave velocity measurements were conducted and estimates of UWS were made based on the KT model for natural Onsøy clay at the tested temperatures. The piezo disc elements, which have around $100 \mathrm{kHz}$ central frequency, were coated with silver paint and grounded to eliminate electrical cross-talk (see details in the paper by Lee \& Santamarina (2005)). These prepared piezo disc crystals (12 $\mathrm{mm}$ dia. and $1.5 \mathrm{~mm}$ thick) were coated with epoxy for water proofing and attached to the inside wall of the $76 \mathrm{~mm}$ dia. acrylic cylinder in which the sample was placed. Two PT-100 sensors (a type of resistance thermistor) with $0 \cdot 1{ }^{\circ} \mathrm{C}$ accuracy and good repeatability were inserted to measure the actual temperature and its spatial variation inside the frozen soil sample (test set-up details can be found in Fig. 4). This set-up has been verified based on the accurate measurement of water acoustic velocity. The whole system was placed
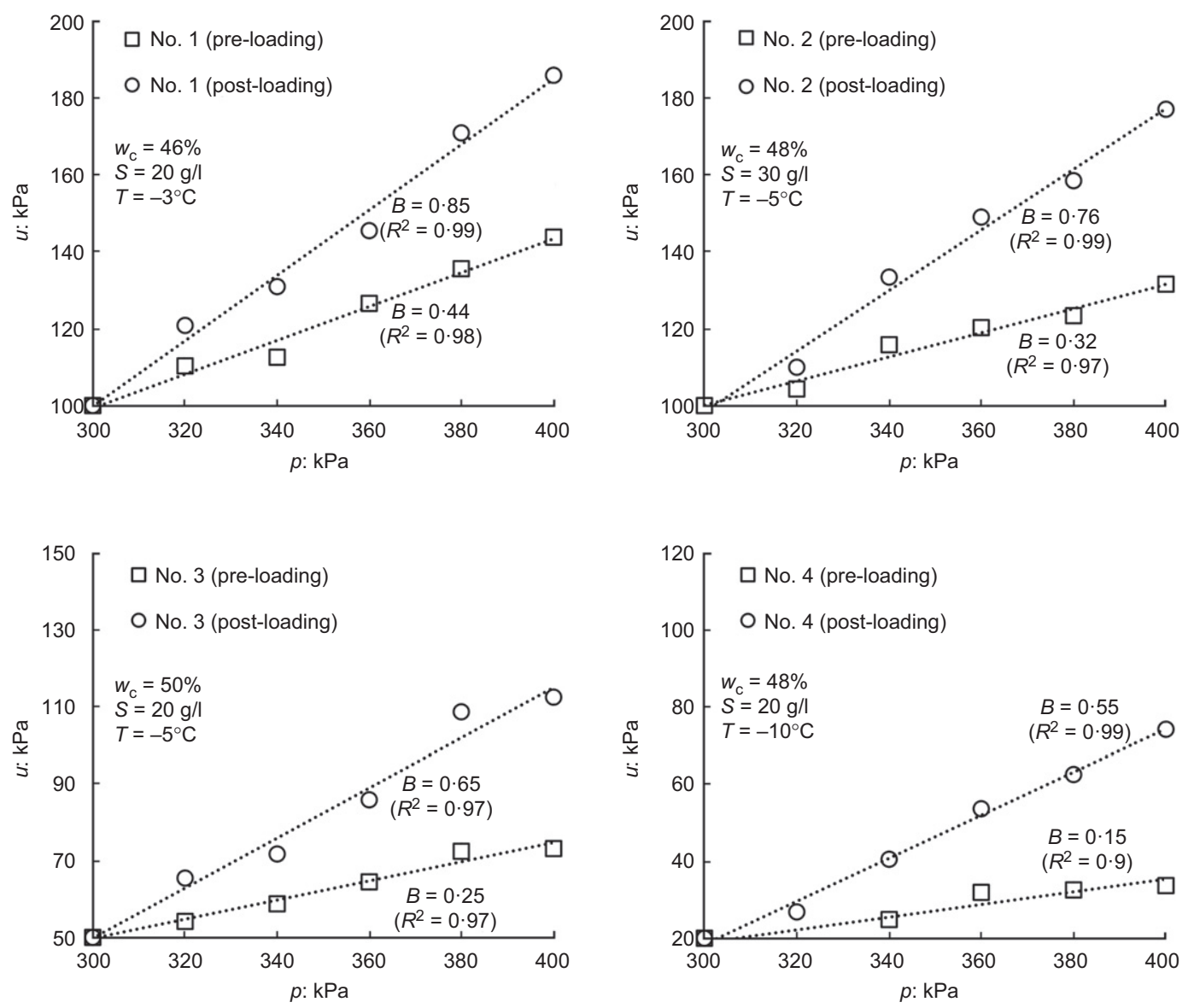

Fig. 3. Pore pressure $u$ plotted against confinement pressure $p$ in the pore pressure coefficient for Onsøy clay. ( $w_{\mathrm{c}}$, water content of unfrozen saturated sample; $S$, salinity; $T$, testing temperature; pre-loading: $B$ value test before triaxial constant-rate loading and unloading; post-loading: $B$ value test after triaxial constant-rate loading and unloading) 


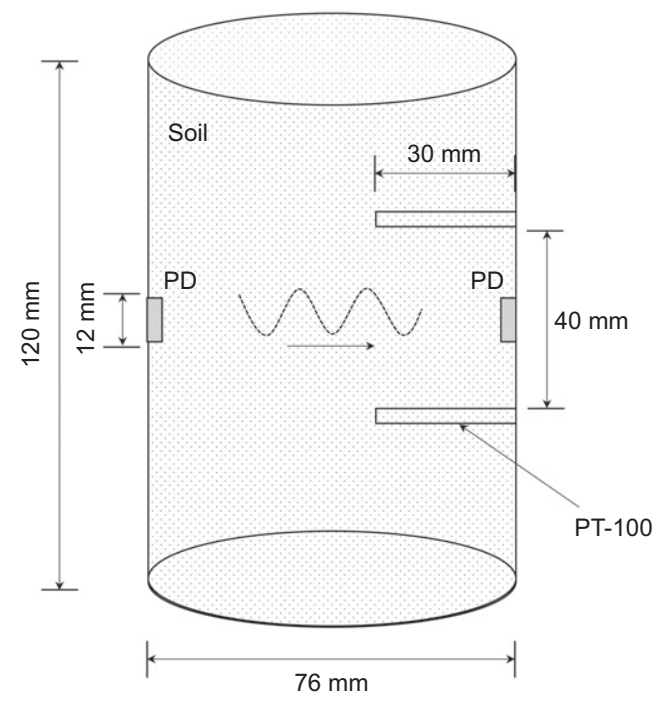

Fig. 4. Set-up sketch of $P$-wave velocity measurement (PD, piezo disc). Note: two PT-100 sensors were inserted inside the soil sample to check the spatial variation of soil temperature. Both measurements show differences within $0 \cdot 1^{\circ} \mathrm{C}$

inside a temperature-controlled freezer to maintain the temperature during the testing. The waveform and measured velocities are presented as a function of temperature in Fig. 5(a) for the tested Onsøy clay with $20 \mathrm{~g} / \mathrm{l}$ salinity and $48 \%$ water content. The KT model (see equations (10) and (11) in the Appendix) was adopted to calculate the undrained moduli of frozen soils and P-wave velocity as a function of UWS ranging from 0 (fully frozen state) to $100 \%$ (fully unfrozen state). The UWS value that corresponds to the measurement result of P-wave velocity was taken as the estimate at a given temperature. The UWS estimate for frozen Onsøy clay is presented in Fig. 5(b) as a function of temperature.

To qualitatively verify the estimate, Fig. 5(b) also shows theoretically calculated UWS plotted against temperature curves for $S=20-40 \mathrm{~g} / \mathrm{l}$ frozen brine according to the thermodynamic equilibrium of water-ice phases. The UWS is expected to remain quite significant, even below $-10^{\circ} \mathrm{C}$ for saline ice, because ions are expelled from freezing ice to unfrozen water and the electrolyte concentration in the remaining unfrozen water increases with ice crystallisation. Therefore, it leads to further freezing point depression of the remaining unfrozen water. In addition, surface effects, such as electrical double layers, are induced by fine-grained particles in frozen soils, and also have a significant contribution to UWS in frozen fine-grained soils. The UWS of Onsøy clay with the combined effects of ions in pore fluid and fine-grained particles should be higher than UWS in saline ice at a given temperature and salinity. As Fig. 5(b) also indicates, the UWS ( $S_{\mathrm{w}}$ plotted against $T$ ) curve of Onsøy clay with $20 \mathrm{~g} / \mathrm{l}$ salinity is between the $S=30 \mathrm{~g} / \mathrm{l}$ and $40 \mathrm{~g} / \mathrm{l}$ frozen brine at a given temperature, which indirectly shows that the interpreted UWS is reasonable. The estimated UWS together with the measured $B$ value for Onsøy clay is presented in Figs 6(a) and 6(b). The results suggest that the $B$ value decreases with a decrease in UWS $(50-100 \%)$.

Kia (2012) also developed a fibre optic rigid piezometer and conducted a $B$ value test for frozen saline Ottawa sand with $30 \mathrm{~g} / \mathrm{l}$ salinity at the range of $100 \mathrm{kPa}$ hydraulic pressure. Combining UWS results measured by Hivon \& Sego (1995), the $B$ value against $S_{\mathrm{w}}$ results for frozen saline Ottawa sand are marked as triangles in Figs 6(c) and 6(d). Similarly to the Onsøy clay, the $B$ value decreased with decreasing UWS, but an opposite trend was observed at UWS below $50 \%$.

\section{THEORETICAL BACKGROUND}

Pore pressure coefficient and Gassmann's equation

The pore pressure coefficient can be written as a function of the fluid bulk modulus $K_{\mathrm{f}}$, the pore bulk modulus $K_{\mathrm{n}}$ (defined in equation (3)), the skeleton modulus $K$, the porosity $n$ and the Biot coefficient $\alpha=1-K / K_{\mathrm{s}}\left(K_{\mathrm{s}}\right.$ : solid bulk modulus defined in equation (4)) for porous media (Gassmann, 1951; Berge et al., 1993; Berge \& Berryman, 1995)

$$
B=\frac{1}{1+(n K / \alpha)\left[\left(1 / K_{\mathrm{f}}\right)-\left(1 / K_{\mathrm{n}}\right)\right]}
$$

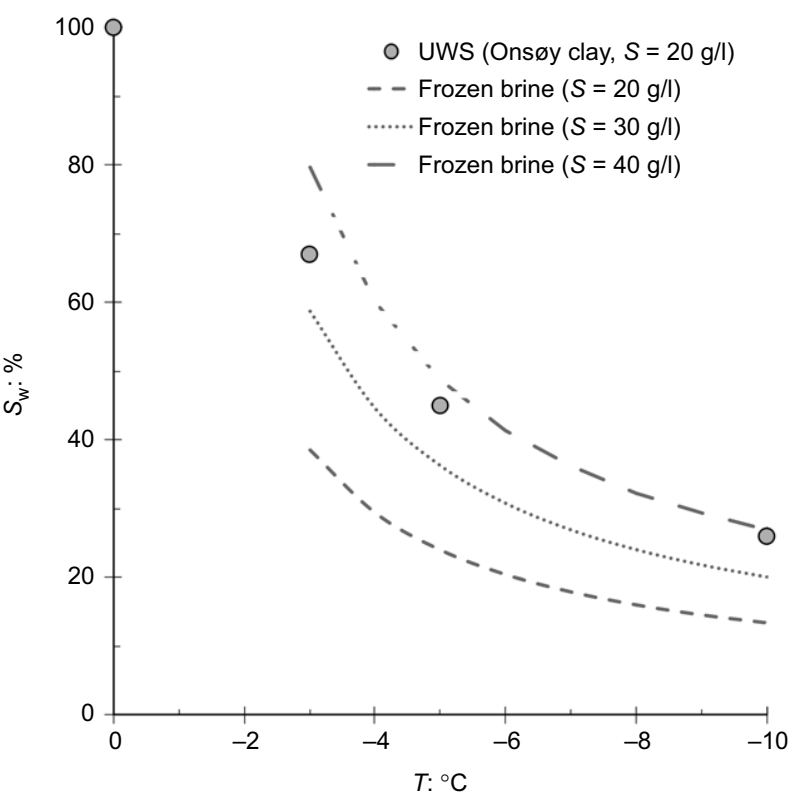

(b)

Fig. 5. P-wave velocity-based UWS estimate: (a) P-wave velocity; (b) $S_{\mathrm{w}}$ plotted against $T$ 

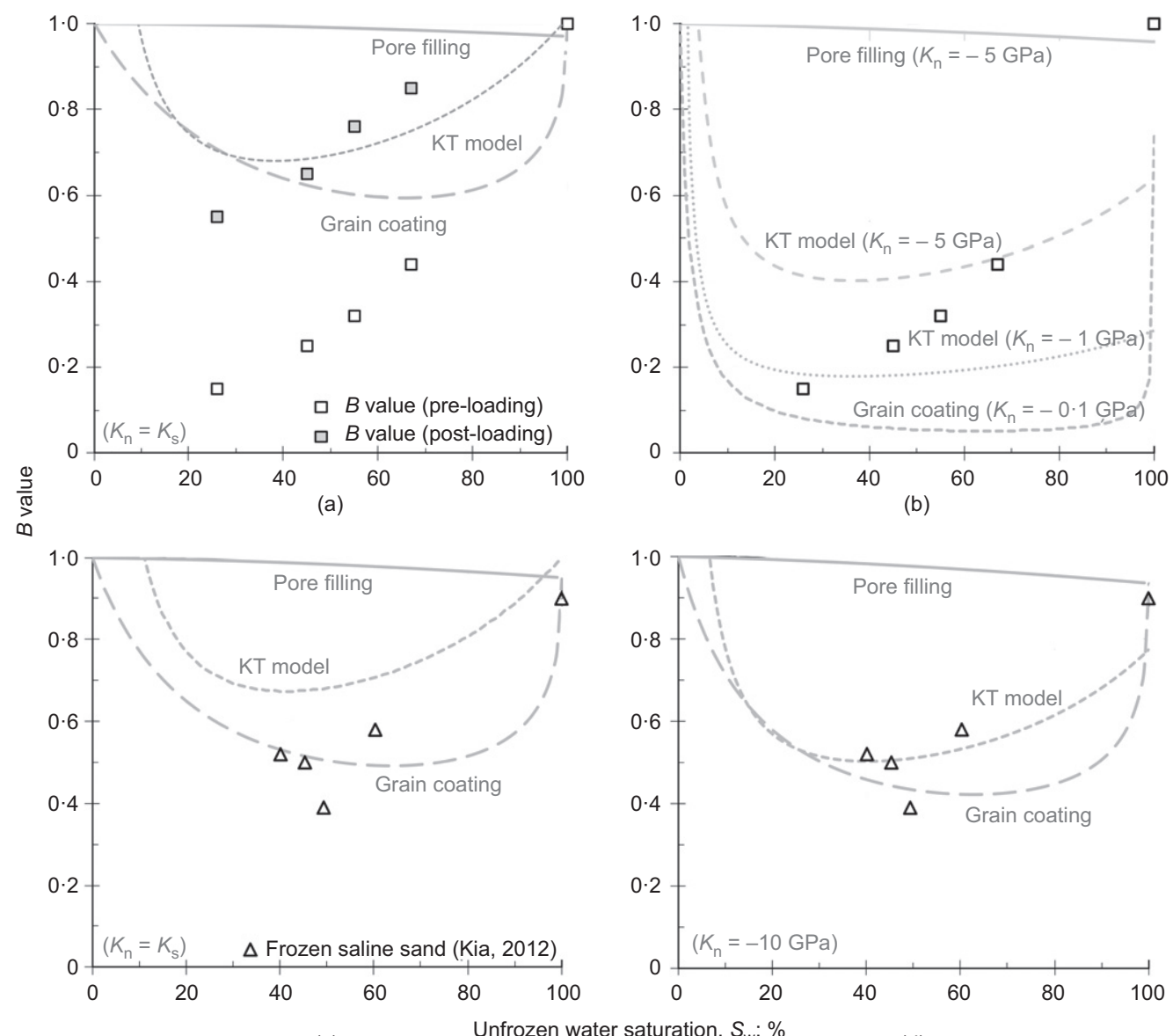

(c)

(d)

Fig. 6. $B$ value plotted against $S_{\mathrm{w}}$ : (a) Gassmann equation $\left(K_{\mathrm{n}}=K_{\mathrm{s}}\right)$ for the $B$ value analysis of frozen Onsøy clay; (b) Gassmann equation (negative $\left.K_{\mathrm{n}}\right)$ for the $B$ value analysis of frozen Onsøy clay; (c) Gassmann equation $\left(K_{\mathrm{n}}=K_{\mathrm{s}}\right)$ for the $B$ value analysis of frozen saline sand (Kia, 2012); (d) Gassmann equation (negative $K_{n}$ ) for the $B$ value analysis of frozen saline sand (Kia, 2012)

$$
\begin{aligned}
& K_{\mathrm{n}}^{-1}=-\frac{1}{n V}\left[\frac{\partial(n V)}{\partial u}\right]_{p^{\prime}=\mathrm{const} .} \\
& K_{\mathrm{s}}^{-1}=-\frac{1}{V}\left(\frac{\partial V}{\partial u}\right)_{p^{\prime}=\text { const. }}
\end{aligned}
$$

where $V$ is the sample volume and $p^{\prime}$ is the Terzaghi mean effective stress defined as $p^{\prime}=p-u$. Here, $p$ is the mean total stress and is defined as the average of three principal stresses $\sigma_{1}, \sigma_{2}$ and $\sigma_{3}$

$$
p=\frac{\sigma_{1}+\sigma_{2}+\sigma_{3}}{3}
$$

Alternatively, $B$ is expressed in terms of $K_{\mathrm{u}}$ (undrained bulk modulus), $K_{\mathrm{s}}$, and $K$ (Brown $\&$ Korringa, 1975)

$$
B=\frac{\left[1-\left(K / K_{\mathrm{u}}\right)\right]}{\left[1-\left(K / K_{\mathrm{s}}\right)\right]}
$$

The $B$ value approaches 1 for unconsolidated, unfrozen porous materials, typically like soils, indicated by equation (6) when $K / K_{\mathrm{s}}, K / K_{\mathrm{u}}$ and $K / K_{\mathrm{f}}$ are sufficiently small, such as $<0 \cdot 01$. Gundersen et al. (2019) concluded that the oedometer modulus for reloading-unloading is around 1-2 $\mathrm{MPa}$ for the natural Onsøy clay above $10 \mathrm{~m}$ depth. The skeleton bulk modulus $K$ is in the range of $0 \cdot 7-1.5 \mathrm{MPa}$ (estimated from the oedometer modulus) and negligible compared with $K_{\mathrm{s}}(20-44 \mathrm{GPa})$ and $K_{\mathrm{w}}(2 \cdot 25 \mathrm{GPa})$. In addition, the value can be closer to 1 for low-porosity porous media with $n \rightarrow 0$ in equation (2) and $K_{\mathrm{u}} \rightarrow K_{\mathrm{s}}$ in equation (6)
(Berge et al., 1993) - for example, $B=0 \cdot 95-1$ for Vermont marble and Barre granite with around $2-3 \%$ porosity at $p^{\prime}=200 \mathrm{kPa}$ (Mesri et al., 1976).

The $B$ value is expected to correlate with porosity $n$, since a decrease in porosity generally leads to an increase of $K$ and $K_{\mathrm{u}}$, and a decrease of $\alpha$ (Lee, 2002), although porosity distribution, microcracks and pore shapes complicate the physical properties of porous media (Mesri et al., 1976; Berge et al., 1993). Some laboratory test results for rocks, as one of the typical porous materials, also indicate this tendency: $B=0.93-0.98$ for $n=0.4$ Nevada Tuff at $p^{\prime}=20-50 \mathrm{MPa}$ (Fredrich et al., 1995), $B=0.68$ for $n=0.19$ for Berea Sandstone at $p^{\prime}=7 \mathrm{MPa}$ (Hart \& Wang, 1995) and $B=0.53-0.69$ at $n=0.13$ for Indiana Limestone at $p^{\prime}=2-10 \mathrm{MPa}$ (Hart \& Wang, 1995). In summary, both theoretical and experimental evidence shows the relationship between porosity and $B$ value, although in addition $p^{\prime}$ plays a significant role. Therefore, ice crystallisation following the decrease in UWS can play an important role in $B$ value variation during freezing.

Gassmann's equation assumes the invariability of $n$ with $u$ to secure $K_{\mathrm{n}}=K_{\mathrm{s}}$ as indicated in equations (3) and (4) for a homogeneous porous medium composed of a monotonic solid phase when $p^{\prime}$ remains constant (Berge, 1998; Hart \& Wang, 2010). However, $K_{\mathrm{n}}$ is not bound by $K_{\mathrm{s}}$ when more than one solid constituent is present (like coexistence of soil particles and ice in frozen soils). This discrepancy becomes significant, and $K_{\mathrm{n}}$ value can theoretically even become negative. It can take place when compressible solid grains (e.g. ice with $8.4 \mathrm{GPa}$ ) fill the pore spaces such as the pore-filling crystallisation mode as seen in Fig. 1, and are 
covered by a five times 'stiffer' solid medium (like quartz with 44 GPa bulk modulus) (Berge \& Berryman, 1995; Helgerud et al., 1999; Hart \& Wang, 2010). Although difficult to measure directly, the back-calculated $K_{\mathrm{n}}$ indicates negative value for rocks composed of quartz and clays with a large stiffness mismatch (Berge, 1998). Similarly, frozen soil can possibly show a negative $K_{\mathrm{n}}$ value because of the large stiffness mismatch and comparable proportion for soil and ice according to the theoretical analysis of Berge \& Berryman (1995).

It is noted that ice bulk stiffness shows slight temperaturedependency and increases by around $1.6 \%$ when the temperature decreases from a freezing temperature down to $-10^{\circ} \mathrm{C}$ (Vogt et al., 2008; Vaughan et al., 2016). For simplicity, $K_{\mathrm{i}}$ is assumed to remain unchanged in the range of the testing temperature $\left(-3\right.$ to $\left.-10^{\circ} \mathrm{C}\right)$ in the current paper. The other issue is the wide stiffness range of clay minerals. Reported theoretical values of clay bulk modulus range from 20 to $50 \mathrm{GPa}$ (Vanorio et al., 2003). The laboratory test results show chemical composition, mineral type and testing method influence the stiffness values of clay minerals. For example, Aleksandrov (1961) and Katahara (1996) suggested 52-56 GPa bulk modulus for illite, kaolinite and chlorite. Han et al. (1986) and Berge \& Berryman (1995) proposed $21.4 \mathrm{GPa}$ bulk modulus for the situation of mixed clay minerals. Wang et al. (2001) measured $60 \cdot 1 \mathrm{GPa}$ for illite and up to $164 \cdot 3 \mathrm{GPa}$ for chlorite (ripidolite) and $127 \mathrm{GPa}$ for $\mathrm{Mg}$-rich chlorite. In this study, the content of different clay minerals and chemical compositions in each mineral remain unknown. For simplicity of analysis, a typical clay bulk stiffness value, $20.9 \mathrm{GPa}$, was adopted to calculate the solid bulk stiffness of Onsøy clay with mixed clay minerals. However, a higher value is expected because laboratory test results suggest much higher stiffness for illite and chlorite minerals, which are the two major clay composites in Onsøy clay. The assumption of $K_{\mathrm{n}}=K_{\mathrm{s}}$ in Gassmann's equation can further deviate from the reality if the stiffness of clay minerals is of the order $100 \mathrm{GPa}$. In the discussion section of this paper (entitled 'Discussion'), the effect of the variation in clay bulk stiffness on the $B$ value of frozen soils will be analysed.

\section{Theoretical approach}

The KT model has been proven to achieve accurate UWS estimates for saline sand and clay (Lyu et al., 2020). The model was used earlier to estimate UWS according to measured P-wave velocities, and here it is used to investigate the likely change in $B$ value with the decrease of UWS and increase in $K$ during freezing. The KT model outputs a $K_{\mathrm{u}}$ estimate (see Appendix), and $K$ as the function of $K_{\mathrm{u}}$ can be back-calculated from the extended Gassmann's equation (Brown \& Korringa, 1975; Berge, 1998)

$$
K=\frac{\left[\left(K_{\mathrm{u}} / K_{\mathrm{s}}\right)+\left(n_{1} K_{\mathrm{u}} / K_{\mathrm{f}}\right)-\left(n_{1} K_{\mathrm{u}} / K_{\mathrm{n}}\right)-1\right]}{\left[\left(K_{\mathrm{u}} / K_{\mathrm{s}}\right)+\left(n_{1} K_{\mathrm{s}} / K_{\mathrm{f}}\right)-\left(n_{1} K_{\mathrm{s}} / K_{\mathrm{n}}\right)-1\right]} K_{\mathrm{s}}
$$

where effective porosity $n_{1}=n S_{\mathrm{w}}$ ranging from 0 (completely frozen) to $n$ (completely unfrozen). The solid bulk and shear moduli, $K_{\mathrm{s}}$ and $G_{\mathrm{s}}$, can be calculated based on the VoigtReuss average suggested by Hill (1952)

$$
\begin{aligned}
& K_{\mathrm{s}}=\frac{1}{2}\left[\sum_{j=1}^{m} f_{j} K_{j}+\left(\sum_{j=1}^{m} f_{j} / K_{j}\right)^{-1}\right], \\
& G_{\mathrm{s}}=\frac{1}{2}\left[\sum_{j=1}^{m} f_{j} G_{j}+\left(\sum_{j=1}^{m} f_{j} / G_{j}\right)^{-1}\right]
\end{aligned}
$$

where $m$ is the number of solid components (ice, clay and quartz); $f_{j}, K_{j}$ and $G_{j}$ are the volumetric fraction, bulk and shear moduli corresponding to the $j$ th component in the solid phase. The ice fraction $f_{\mathrm{i}}$ increases and, correspondingly, quartz and clay volumetric fractions $f_{\mathrm{q}}$ and $f_{\mathrm{c}}$ decrease with freezing, which can be calculated as follows

$$
\begin{aligned}
& f_{\mathrm{q}}=C_{\mathrm{q}}(1-n) /\left(1-n_{1}\right) ; \\
& f_{\mathrm{c}}=C_{\mathrm{c}}(1-n) /\left(1-n_{1}\right) ; f_{\mathrm{i}}=n\left(1-S_{\mathrm{w}}\right) /\left(1-n_{1}\right)
\end{aligned}
$$

where $C_{\mathrm{q}}=V_{\mathrm{q}} /\left(V_{\mathrm{c}}+V_{\mathrm{q}}\right)$ and $C_{\mathrm{c}}=V_{\mathrm{c}} /\left(V_{\mathrm{c}}+V_{\mathrm{q}}\right)$. The quartz and clay volumetric content, $V_{\mathrm{q}}$ and $V_{\mathrm{c}}$, are defined in Fig. 1(b).

Frozen soils can typically consist of various microstructures such as ice growing in the pore space, coating soil particles, or ice enveloped by soil particles. Soil particles can maintain contact with each other, or ice can invade, and split particles apart, as suggested in Fig. 1(a). In order to simplify the complexity, this work considers two monotonic ice crystallisation modes: the pore filling and grain coating models, as 'very' weak and strong $K$ evolution modes with freezing, suggest upper and lower bounds of $B$ value with soil freezing, respectively. It should be noted that there is always a thin layer of water molecules between ice and fine-grained soil particles as seen in Fig. 1(a). This indicates that the grain coating model essentially deviates from reality, especially when it is applied to Onsøy clay. However, it can be suggested as a scenario to provide the upper boundary of skeleton stiffness $K$. The detailed calculations regarding the $B$ value as a function of UWS are presented here. Similarly to the KT model, both equations (8) and (9) were used again to first update $K_{\mathrm{s}}$ with the variation of $S_{\mathrm{w}}$. A set of equations (14)-(17) and (19)-(22) (in the Appendix) was then adopted to calculate skeleton bulk modulus $K$ at a given ice crystallisation mode (pore filling or grain coating). Finally, the extended Gassmann equation (18) was applied to calculate $K_{\mathrm{u}}$ from the $K$ value, and relevant bulk moduli were introduced into either equation (2) or (6) to obtain the $B$ value at a given $S_{\mathrm{w}}$. It should be noted that the original studies (Dvorkin \& Nur, 1996; Helgerud et al., 1999) applied Gassmann's equation (assuming $K_{\mathrm{n}}=K_{\mathrm{s}}$ ). Instead, this paper highlights the extended Gassmann equation with the relaxation of $K_{\mathrm{n}}=K_{\mathrm{s}}$ assumption to calculate $K_{\mathrm{u}}$ from $K$ in order to consider the effect of $K_{\mathrm{n}}$ on the $B$ value of frozen soils in the discussion (Brown \& Korringa, 1975). The key equations of the KT, pore filling and grain coating models can be found in the Appendix.

Table 1 presents the input parameters for the three models and other properties for Ottawa sand and Onsøy clay. In addition, two more parameters in the grain coating and pore filling models are also determined as coordination number $(\mathrm{CN}=9)$ and critical porosity $\left(n_{\mathrm{c}}=0 \cdot 37\right)$, for an assumed case of $p^{\prime}=100 \mathrm{kPa}$, according to Helgerud et al. (1999). The lines in Figs 6(a) and 6(c) present diverse $B$ value plotted against $S_{\mathrm{w}}$ variation by assuming $K_{\mathrm{n}}=K_{\mathrm{s}}$, and Figs 6(b) and 6(d) present the results with relaxation of the $K_{\mathrm{n}}=K_{\mathrm{s}}$ assumption.

\section{DISCUSSION}

Effect of pore compressibility

Generally, both theoretical and experimental results suggest a decrease in $B$ value with lowering UWS from $100 \%$ to $40-60 \%$. The measured $B$ value of frozen Ottawa sand in Fig. 6(c) seems to follow the lower bound suggested by the grain coating mode when $K_{\mathrm{n}}=K_{\mathrm{s}}$ is assumed. However, this ice crystallisation mode only has been shown to be unlikely to occur (Dou et al., 2017; Lyu et al., 2020). Furthermore, the measured pre-loading $B$ value for frozen Onsøy clay is even below this lower bound suggested by the grain coating mode as indicated in Fig. 6(a). Although more 
Table 1. Material properties for frozen soil

\begin{tabular}{l|c|l|l}
\hline Material & $K: \mathrm{GPa}$ & $G: \mathrm{GPa}$ & $\rho: \mathrm{kg} / \mathrm{m}^{3}$ \\
\hline Water & $2 \cdot 25^{*}$ & 0 & $1000^{*}$ \\
Quartz & $44 \dagger$ & $37 \dagger$ & $2650 \dagger$ \\
Clay & $20 \cdot 9+$ & $6 \cdot 85 \dagger$ & $2580 \dagger$ \\
Ice & $8 \cdot 4^{\S}$ & $3 \cdot 7^{\S}$ & $920^{\S}$ \\
Soil types & $n$ & $C_{\mathrm{c}}$ & $S: \mathrm{g} / 1$ \\
Ottawa sand & $0 \cdot 42$ & $0 *$ & 30 \\
Onsøy clay & $0 \cdot 58$ & $0 \cdot 5$ & $20 / 30$ \\
\hline
\end{tabular}

Note: $K$, bulk modulus; $G$, bulk modulus; $\rho$, density; $n$, soil porosity; $C_{\mathrm{c}}$, clay volumetric fraction; $S$, salinity.

*Leclaire et al. (1994).

$\dagger$ Zimmerman \& King (1986).

tChand et al. (2004).

${ }^{\S}$ Lee et al. (1996).

${ }^{\|}$Kia (2012).

pore pressure coefficient measurements should be conducted for frozen soils, the fact that both $B$ value results deviate from the KT model indicates the possibility of $K_{\mathrm{n}} \neq K_{\mathrm{s}}$, and even a negative $K_{\mathrm{n}}$ value for frozen soils. With the relaxation of the $K_{\mathrm{n}}=K_{\mathrm{s}}$ assumption, the proper $K_{\mathrm{n}}$ values were sought to make the $B$ value variation estimated by the KT model consistent with the measurement results. Fig. 6(d) suggests $K_{\mathrm{n}}=-10 \mathrm{GPa}$ to reach the general consistency between experimental results and the KT model for frozen Ottawa sand. Various negative values of $K_{\mathrm{n}}$ with the range from -1 to $-5 \mathrm{GPa}$ are indicated for frozen Onsøy clay in Fig. 6(b). However, this consistency would not be taken as the definitive support for negative $K_{\mathrm{n}}$ values. Here, the experimental data are explained by a $K_{\mathrm{n}}$ that is variable with mostly negative values according to the UWS. Further measurement for parameter sets (e.g. $K_{\mathrm{u}}, K$ and $B$ value) is recommended to minimise the error influence of a single parameter measurement and to reach a more accurate estimate of $K_{\mathrm{n}}$ (Hart \& Wang, 2010).

\section{Loading history dependency}

In addition to UWS (or temperature) dependency, the present study also found the significant increase in $B$ value after loading-unloading, which is an important finding in the paper. Two possible mechanisms can contribute to this phenomenon. First, $K$ can become significantly smaller because of ice crystal crushing during the loading-unloading phase. Dai \& Santamarina (2017) also reported stiffness loss as a consequence of creep and loading-unloading based on the evolution of P-wave velocity. The other possible reason is the loading history induced $K_{\mathrm{n}}$ evolution. As Fig. 6(a) suggests, the post-loading $B$ value of Onsøy clay is enveloped by the upper and lower bounds suggested by pore filling and grain coating, respectively, when $K_{\mathrm{n}}=K_{\mathrm{s}}$ is assumed. The negative value of $K_{\mathrm{n}}$ occurs in some specific soil-ice microstructures as mentioned above, and this structure can be highly degraded during different loading processes. However, more evidence is needed to confirm these explanations.

\section{Effect of the variation in clay mineral stiffness}

As suggested in the earlier section entitled 'Pore pressure coefficient and Gassmann's equation', a wide range of bulk stiffness values for clay minerals has been reported in the literature, and the solid bulk stiffness for Onsøy clay is likely to be higher than the $20.9 \mathrm{GPa}$ adopted in this work. Therefore, it is meaningful to study the effect of variation in clay mineral stiffness on the $B$ value for frozen soils. In this discussion, four scenarios are proposed with different clay mineral stiffness: $(a) K_{\mathrm{c}}=10 \mathrm{GPa}, G_{\mathrm{c}}=5 \mathrm{GPa}$ (lower bound of clay stiffness); (b) $K_{\mathrm{c}}=20.9 \mathrm{GPa}, G_{\mathrm{c}}=6.85 \mathrm{GPa}$ (typical value for mixed clay minerals); (c) $K_{\mathrm{c}}=60 \cdot 1 \mathrm{GPa}$, $G_{\mathrm{c}}=25 \cdot 3 \mathrm{GPa}$ (illite stiffness measured by Wang et al. (2001)); (d) $K_{\mathrm{c}}=127 \mathrm{GPa}, G_{\mathrm{c}}=82 \mathrm{GPa}$ (Mg-rich chlorite stiffness measured by Wang et al. (2001)). The calculated $B$ values are presented in Fig. 7 for four different clay stiffness scenarios based on KT when $K_{\mathrm{n}}=K_{\mathrm{s}}$ and $K_{\mathrm{n}}=-5 \mathrm{GPa}$. As the results indicate, the clay stiffness shows some influence on the $B$ value of frozen soil, and a maximum variation of $\approx 0.15$ in the $B$ value is suggested with the wide variation of clay stiffness. Besides, the $B$ value at low UWS (less than $30 \%$ ) was more influenced by the variation in clay stiffness compared with at high UWS (above 60\%).

\section{UWS estimate and limitation of the KT model and Gassmann's equation}

The KT model was developed to simulate the elasticity of unconsolidated permafrost (King et al., 1988), and it was

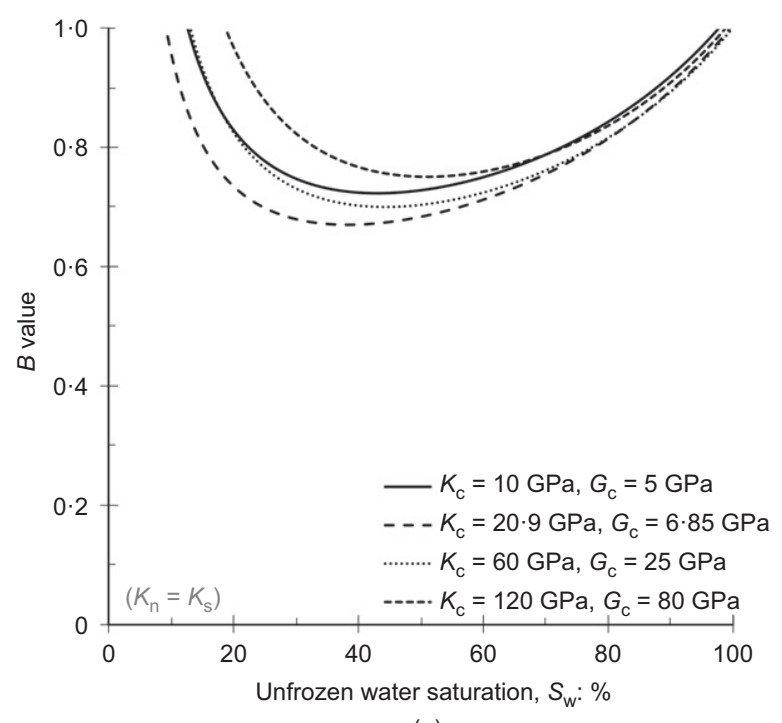

(a)

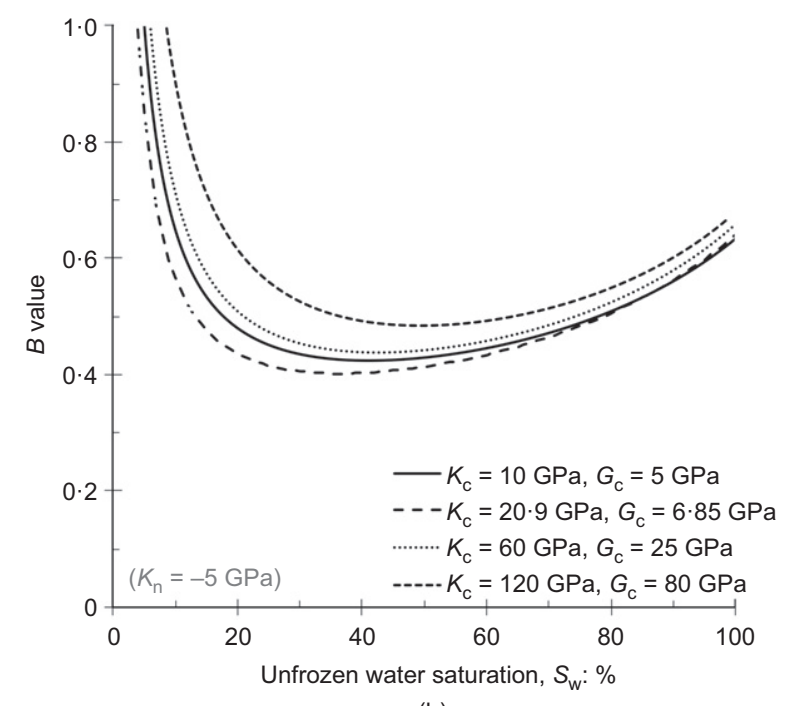

(b)

Fig. 7. $B$ value change with clay stiffness $\left(K_{\mathrm{c}}\right.$ and $\left.G_{\mathrm{c}}\right)$ variation as an example of Onsøy clay: (a) $K_{\mathrm{n}}=K_{\mathrm{s}}$; (b) $K_{\mathrm{n}}=-5 \mathrm{GPa}$ 


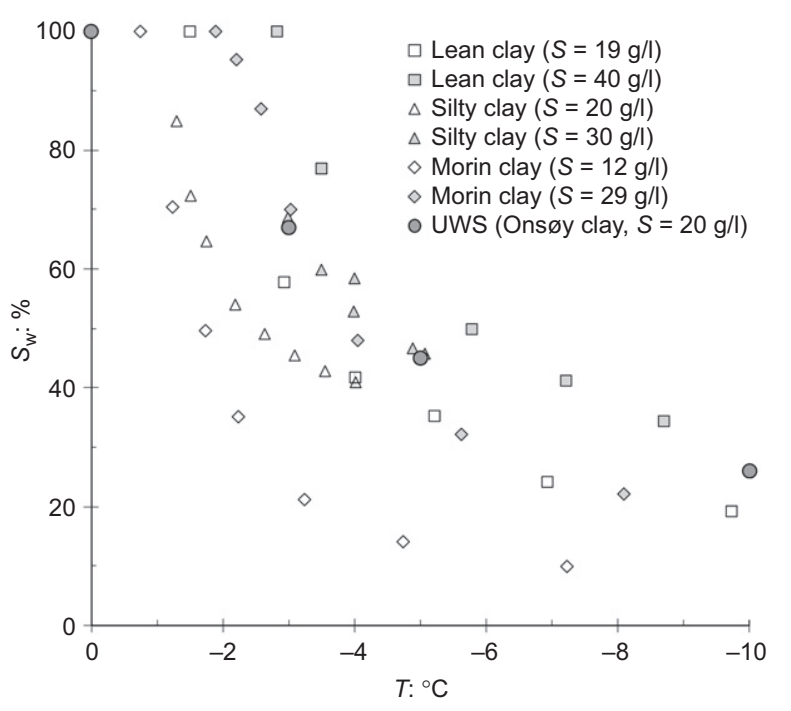

Fig. 8. $S_{\mathrm{w}}$ plotted against $\boldsymbol{T}$ for different types of frozen saline clay: lean clay $(S=19 \mathrm{~g} / \mathrm{l}$ and $40 \mathrm{~g} / \mathrm{l})$ with $15 \%$ clay and $85 \%$ silt content (Liu et al., 2020); silty clay $(S=20 \mathrm{~g} / \mathrm{l}$ and $30 \mathrm{~g} / \mathrm{l})$ with unknown clay and silt content (Patterson \& Smith, 1985); Morin clay $(S=12 \mathrm{~g} / \mathrm{l}$ and $29 \mathrm{~g} / \mathrm{l})$ with $12.5 \%$ clay content and $72.9 \%$ silt content (Zhou et al., 2020)

used for UWS estimates in this paper because it requires a very limited number of parameters and has been widely adopted (Kneisel et al., 2008; Hauck et al., 2011). However, this model only takes spherical shapes of water and soil phases into consideration, which deviates from the geometry of natural clay particles. In order to study the capability of the KT model for UWS estimation, Lyu et al. (2020) conducted a systematic comparison between the KT model estimate and UWS measurement results for a wide range of soil types. They found that the KT model can achieve quite an accurate UWS estimate for saline unconsolidated sand and saline Boom clay based on P-wave velocity measurement. This indicates an insignificant shape effect of 'hard inclusions' (soil particles in frozen soils) on the UWS estimate. To further investigate the accuracy of the UWS estimate, the UWS plotted against temperature for different types of frozen saline clay with various salinity is also summarised and presented together with Onsøy clay data in Fig. 8. The UWS for $S=20 \mathrm{~g} / \mathrm{l}$ Onsøy clay as a function of temperature is comparable with silty clay with $S=30 \mathrm{~g} / 1$ (Patterson \& Smith, 1985) and Morin clay $(S=29 \mathrm{~g} / \mathrm{l})$ (Zhou et al., 2020) in the range from -3 to $-10^{\circ} \mathrm{C}$. Although Onsøy clay has lower salinity compared with the other two types of soils, there is a much higher clay content in Onsøy clay compared with Morin clay (50\% against $12 \cdot 5 \%$ ). In addition, the UWS of lean clay with $S=19 \mathrm{~g} / \mathrm{l}$ is slightly lower than that of Onsøy clay $(S=20 \mathrm{~g} / \mathrm{l})$, because the clay content of the former soil type is also lower than that of the latter soil type. To sum up, Fig. 8 proves the coupled effects of ion concentration in pore fluid and clay or fine content on UWS. The UWS estimate of Onsøy clay appears to have reasonable accuracy.

It should also be noted that the Gassmann equation has been adopted throughout this study. However, it assumes well-connected pore spaces, which can be violated for frozen soil with low UWS, although the adopted generalised Gassmann equation in this study already relaxes the assumption of isotropy, monomineral solid phase and homogeneity (Smith et al., 2003). As well as the research on the $B$ value of frozen soil, there are quite a few studies on the validation of the Gassmann equation on low-UWS frozen soils, or even on other types of porous material - for example, rocks. Han et al. (1986) and Han \& Batzle (2004) suggested the validity of the Gassmann equation for sandstone samples above $n=0 \cdot 15$, and estimated that errors of bulk modulus below $n=0 \cdot 15$ become more significant with the decrease in porosity. This also indicates that the relation between $B$ value and UWS shown in Figs 6 and 7 can deviate from reality when UWS is below $20-30 \%$. However, the $B$ value approaches 1 when effective porosity $n_{1}$ becomes closer to 0 based on the previous analysis and reported experimental results. This suggests that the tendency towards $B$ value variation in UWS below $20-30 \%$ could be reasonable even when it is analysed based on the Gassmann equation. Further study regarding new model development is necessary to have a better understanding of the $B$ value for frozen soils.

\section{CONCLUSIONS}

This study presents a systematic work regarding the $B$ value testing of frozen soils. It includes a 'slow-freezing' preparation of artificial frozen samples and an experimental framework for pore pressure measurement in frozen soils. In addition, P-wave velocity was successfully measured for frozen Onsøy clay, and the KT model was applied to estimate UWS as a function of temperature. The UWS comparison for different frozen saline clays indirectly proves the reasonable accuracy of the estimate for Onsøy clay. In addition, this study draws several other original conclusions, as outlined below.

The $B$ value of frozen soil shows temperature dependency. Both experimental results and theoretical analysis suggest a decrease in $B$ value with lower UWS from $100 \%$ (completely unfrozen) to $40-50 \%$, as the temperature drops.

The deviation of the $B$ value between the measurement results presented and theoretical analysis suggests $K_{\mathrm{n}} \neq K_{\mathrm{s}}$, and that $K_{\mathrm{n}}$ can vary with UWS and even take a negative value.

The $B$ value of frozen soils also shows a loading history dependency. This is likely to be induced by a loss in skeleton stiffness as the pore stiffness approaches the solid stiffness due to microstructure evolution.

A wide range of clay stiffness can contribute limited impact on the $B$ value of frozen Onsøy clays, and this influence is more significant at low UWS (less than 30\%) compared with high UWS (above 60\%).

\section{ACKNOWLEDGEMENTS}

This publication is part of the Nunataryuk project. The project has received funding under the European Union's Horizon 2020 Research and Innovation Programme under grant agreement no. 773421. The first author would like to acknowledge the Norwegian Geotechnical Institute (NGI) for providing soil samples. The authors also appreciate paper proofing and comments provided by Michael Long, Associated Professor at University College Dublin.

\section{APPENDIX. KEY EQUATIONS IN THE KT, PORE FILLING AND GRAIN COATING MODELS}

The 'KT model' suggests the undrained bulk and shear moduli, $K_{\mathrm{u}}$ and $G_{\mathrm{u}}$, for a two-phase medium composed of spherical inclusions (with moduli $K_{\text {in }}$ and $G_{\text {in }}$ ) embedded in a continuous matrix medium (with moduli $K_{\mathrm{ma}}$ and $G_{\mathrm{ma}}$ )

$$
\begin{aligned}
\frac{K_{\mathrm{u}}}{K_{\mathrm{ma}}} & =\frac{1+\left[4 G_{\mathrm{ma}}\left(K_{\text {in }}-K_{\mathrm{ma}}\right) /\left(3 K_{\text {in }}+4 G_{\mathrm{ma}}\right) K_{\mathrm{ma}}\right] c}{1-\left[3\left(K_{\mathrm{in}}-K_{\mathrm{ma}}\right) /\left(3 K_{\mathrm{in}}+4 G_{\mathrm{ma}}\right)\right] c} \\
\frac{G_{\mathrm{u}}}{G_{\mathrm{ma}}} & =\frac{6 G_{\text {in }}\left(K_{\mathrm{ma}}+2 G_{\mathrm{ma}}\right)+\left(9 K_{\mathrm{ma}}+8 G_{\mathrm{ma}}\right)\left[(1-c) G_{\mathrm{ma}}+c G_{\text {in }}\right]}{G_{\mathrm{ma}}\left(9 K_{\mathrm{ma}}+8 G_{\mathrm{ma}}\right)+6\left(K_{\mathrm{ma}}+2 G_{\mathrm{ma}}\right)\left[(1-c) G_{\text {in }}+c G_{\mathrm{ma}}\right]}
\end{aligned}
$$


where $c$ is the volumetric fraction of spherical inclusions.

As Zimmerman \& King (1986) and King (1984) suggested, equations (10) and (11) are adopted iteratively to first estimate the effective moduli of the ice-water mixture by embedding spherical water inclusions into a continuous ice phase and further to calculate the moduli of frozen soil composed of spherical soil grains built into the ice-water mixture

The frozen soil density $\rho_{\mathrm{m}}$ and estimated P-wave velocity $V_{\mathrm{p}}$ as a function of $S_{\mathrm{w}}$ are further calculated as follows

$$
\rho_{\mathrm{m}}=C_{\mathrm{c}}(1-n) \rho_{\mathrm{c}}+\left(1-C_{\mathrm{q}}\right)(1-n) \rho_{\mathrm{q}}+S_{\mathrm{w}} n \rho_{\mathrm{w}}+\left(1-S_{\mathrm{w}}\right) n \rho_{\mathrm{i}}
$$

$$
V_{\mathrm{p}}=\sqrt{\frac{K_{\mathrm{u}}+4 / 3 G_{\mathrm{u}}}{\rho_{\mathrm{m}}}}
$$

where $\rho_{\mathrm{c}}, \rho_{\mathrm{q}}, \rho_{\mathrm{w}}$ and $\rho_{\mathrm{i}}$ are clay, quartz, water and ice densities. At given inputs of $C_{\mathrm{c}}$ and $n$, the $S_{\mathrm{w}}$ value can be determined when the corresponding estimated $V_{\mathrm{p}}$ is consistent with the measurement result. The skeleton bulk modulus $K$ can be back-calculated using equation (7), as discussed in the main text of the paper.

The 'pore filling model' was developed from Hertz-Mindlin contact theory to estimate skeleton bulk modulus $K$ with the consideration of soil particle state, consolidation or suspension, which is distinguished by a critical porosity $n_{\mathrm{c}}$ (Dvorkin \& Nur, 1996; Helgerud et al., 1999)

$$
K= \begin{cases}{\left[\frac{n / n_{\mathrm{c}}}{K_{\mathrm{HM}}+4 / 3 G_{\mathrm{HM}}}+\frac{1-\left(n / n_{\mathrm{c}}\right)}{K_{\mathrm{s}}+4 / 3 G_{\mathrm{HM}}}\right]^{-1}-\frac{4}{3} G_{\mathrm{HM}}} & n<n_{\mathrm{c}} \\ {\left[\frac{(1-n) /\left(1-n_{\mathrm{c}}\right)}{K_{\mathrm{HM}}+4 / 3 G_{\mathrm{HM}}}+\frac{\left(n-n_{\mathrm{c}}\right) /\left(1-n_{\mathrm{c}}\right)}{4 / 3 G_{\mathrm{HM}}}\right]^{-1}-\frac{4}{3} G_{\mathrm{HM}}} & n \geq n_{\mathrm{c}}\end{cases}
$$

where $K_{\mathrm{HM}}$ and $G_{\mathrm{HM}}$ are calculated as per the following equations $(15)$ and $(16)\left(\mathrm{CN}\right.$, coordinator number; $P$, effective stress; $v_{\mathrm{s}}$, solid Poisson's ratio)

$$
\begin{aligned}
K_{\mathrm{HM}} & =\left[\frac{\mathrm{CN}^{2}\left(1-n_{\mathrm{c}}\right)^{2} G_{\mathrm{s}}^{2}}{18 \pi^{2}\left(1-v_{\mathrm{s}}\right)^{2}} P\right]^{1 / 3} \\
G_{\mathrm{HM}} & =\frac{5-4 v_{\mathrm{s}}}{5\left(2-v_{\mathrm{s}}\right)}\left[\frac{3 \mathrm{CN}^{2}\left(1-n_{\mathrm{c}}\right)^{2} G_{\mathrm{s}}^{2}}{2 \pi^{2}\left(1-v_{\mathrm{s}}\right)^{2}} P\right]^{1 / 3}
\end{aligned}
$$

In the pore filling model, the ice phase is assigned as a fluid phase, and the fluid bulk modulus, $K_{\mathrm{f}}$, is a weighted reciprocal average of water and ice bulk moduli $\left(K_{\mathrm{w}}\right.$ and $\left.K_{\mathrm{i}}\right)$ according to UWS

$$
K_{\mathrm{f}}=\left[\left(1-S_{\mathrm{w}}\right) / K_{\mathrm{i}}+S_{\mathrm{w}} / K_{\mathrm{w}}\right]^{-1}
$$

Instead of the original Gassmann's equation, the extended Gassmann equation (18) was adopted by the relaxation of the $K_{\mathrm{n}}=K_{\mathrm{s}}$ assumption to calculate the undrained bulk modulus $K_{\mathrm{u}}$ from skeleton modulus $K$ (Brown \& Korringa, 1975; Berge, 1998; Hart \& Wang, 2010)

$$
K_{\mathrm{u}}=K+\frac{\left[1-\left(K / K_{\mathrm{s}}\right)\right]^{2}}{\left[\left(K_{\mathrm{s}}-K\right) / K_{\mathrm{s}}^{2}\right]+n_{1}\left[\left(1 / K_{\mathrm{f}}\right)-\left(1 / K_{\mathrm{n}}\right)\right]}
$$

Regarding the 'grain coating model', $K$ can be calculated following equation (19)

$$
K=\frac{\mathrm{CN}(1-n)}{6} M_{\mathrm{i}} S(\psi)
$$

where the ice constraint modulus $M_{\mathrm{i}}$ and the parameter $S(\psi)$ can be obtained as follows

$$
\begin{aligned}
& M_{\mathrm{i}}=\frac{4}{3} K_{\mathrm{i}}+G_{\mathrm{i}} \\
& \psi=\left[\frac{2\left(1-S_{\mathrm{w}}\right) n}{3 \mathrm{CN}(1-n)}\right]^{0.5}
\end{aligned}
$$

$$
\begin{aligned}
\Lambda & =\frac{2 G_{\mathrm{i}}}{\pi G_{\mathrm{s}}} \frac{\left(1-v_{\mathrm{g}}\right)\left(1-v_{\mathrm{i}}\right)}{\left(1-2 v_{\mathrm{i}}\right)} \\
A & =-0.024153 \Lambda^{-1.3646} \\
B & =0 \cdot 20405 \Lambda^{-0.89008} \\
C & =0.00024649 \Lambda^{-1.9864} \\
S & =A \psi^{2}+B \psi+C
\end{aligned}
$$

where the $v_{\mathrm{i}}$ are $v_{\mathrm{g}}$ are ice and grain (sand and clay) Poisson's ratio.

\section{NOTATION}

$B$ pore pressure coefficient

$C_{\mathrm{c}}$ clay volumetric content

$C_{\mathrm{q}} \quad$ quartz volumetric content

$f_{\mathrm{i}}, f_{\mathrm{q}}, f_{\mathrm{c}}$ ice, quartz and clay volumetric fraction

$f_{j}, K_{j}, G_{j}$ volumetric fraction, bulk and shear moduli corresponding to the $j$ th component in the solid phase

$G_{\mathrm{w}}, G_{\mathrm{i}}, G_{\mathrm{c}}, G_{\mathrm{q}}$ water, ice, clay and quartz shear modulus

$K$ skeleton modulus

$K_{\mathrm{u}}, K_{\mathrm{f}}, K_{\mathrm{n}}, K_{\mathrm{s}}$ undrained, fluid, pore and solid bulk modulus

$K_{\mathrm{w}}, K_{\mathrm{i}}, K_{\mathrm{c}}, K_{\mathrm{q}} \quad$ water, ice, clay and quartz bulk modulus

$M_{\mathrm{i}} \quad$ ice constraint modulus

$n$ porosity

$n_{\mathrm{c}} \quad$ critical porosity

$P$ effective stress

$p$ confinement pressure

$p^{\prime} \quad$ Terzaghi mean effective stress

$S$ salinity

$S_{\mathrm{w}} \quad$ unfrozen water saturation (UWS)

$u$ pore pressure

$V$ sample volume

$V_{\mathrm{p}} \quad$ estimated P-wave velocity

$\alpha$ Biot coefficient

$v_{\mathrm{g}}$ grain (sand and clay) Poisson's ratio

$v_{\mathrm{i}}$ ice Poisson's ratio

$v_{\mathrm{s}}$ solid Poisson's ratio

$\rho_{\mathrm{w}}, \rho_{\mathrm{i}}, \rho_{\mathrm{c}}, \rho_{\mathrm{q}} \quad$ water, ice, clay and quartz density

\section{REFERENCES}

Aleksandrov, K. (1961). The elastic properties of rock forming minerals II: layered silicates. Bull. Acad. Sci. USSR, Geophys. Ser. 9, 1165-1168.

Arenson, L. U. \& Springman, S. M. (2005). Triaxial constant stress and constant strain rate tests on ice-rich permafrost samples. Can. Geotech. J. 42, No. 2, 412-430.

Berge, P. (1998). Pore compressibility in rocks. In Poromechanics: proceedings of the Biot conference on poromechanics (eds J.-G. Thimus, Y. Aboudeiman, A. H.-D. Cheng, O. Coussy and E. Detournay), pp. 351-356. Abingdon, UK: Taylor \& Francis.

Berge, P. A. \& Berryman, J. G. (1995). Realizability of negative pore compressibility in poroelastic composites. J. Appl. Mech. 62, No. 4, 1053-1062.

Berge, P., Wang, H. \& Bonner, B. (1993). Pore pressure buildup coefficient in synthetic and natural sandstones. Int. J. Rock Mech. Min. Sci. Geomech. Abstr. 30, No. 7, 1135-1141.

Berryman, J. G. (1992). Effective stress for transport properties of inhomogeneous porous rock. J. Geophys. Res.: Solid Earth 97, No. B12, 17409-17424.

Berryman, J. G. \& Milton, G. W. (1991). Exact results for generalized Gassmann's equations in composite porous media with two constituents. Geophysics 56, No. 12, 1950-1960.

Bishop, A. (1976). The influence of system compressibility on the observed pore-pressure response to an undrained change in stress in saturated rock. Géotechnique 26, No. 2, 371-375, https://doi.org/10.1680/geot.1976.26.2.371.

Brown, R. J. \& Korringa, J. (1975). On the dependence of the elastic properties of a porous rock on the compressibility of the pore fluid. Geophysics 40, No. 4, 608-616.

Chand, S., Minshull, T. A., Gei, D. \& Carcione, J. M. (2004). Elastic velocity models for gas-hydrate-bearing sediments - a comparison. Geophys. J. Int. 159, No. 2, 573-590. 
Dai, S. \& Santamarina, J. C. (2017). Stiffness evolution in frozen sands subjected to stress changes. J. Geotech. Geoenviron. Engng 143, No. 9, 04017042.

Dou, S., Nakagawa, S., Dreger, D. \& Ajo-Franklin, J. (2017). An effective-medium model for P-wave velocities of saturated, unconsolidated saline permafrost. Geophysics 82, No. 3, En33-En50.

Dramis, F., Govi, M., Guglielmin, M. \& Mortara, G. (1995). Mountain permafrost and slope instability in the Italian Alps: the Val Pola landslide. Permafr. Periglac. Processes 6, No. 1, 73-81.

Dvorkin, J. \& Nur, A. (1996). Elasticity of high-porosity sandstones: theory for two North Sea data sets. Geophysics 61, No. 5, 1363-1370.

Dvorkin, J., Berryman, J. \& Nur, A. (1999). Elastic moduli of cemented sphere packs. Mech. Mater. 31, No. 7, 461-469.

Ecker, C., Dvorkin, J. \& Nur, A. (1998). Sediments with gas hydrates: internal structure from seismic AVO. Geophysics 63, No. 5, 1659-1669.

Fredrich, J., Martin, J. \& Clayton, R. (1995). Induced pore pressure response during undrained deformation of tuff and sandstone. Mech. Mater. 20, No. 2, 95-104.

Gassmann, F. (1951). Elasticity of porous media. Vierteljahresschr. Naturforsch. Ges. 96, 1-23.

Ghoreishian Amiri, S. A., Grimstad, G., Kadivar, M. \& Nordal, S. (2016). Constitutive model for rate-independent behavior of saturated frozen soils. Can. Geotech. J. 53, No. 10, 1646-1657.

Gundersen, A., Hansen, R., Lunne, T., L'Heureux, J. S. \& Strandvik, O. S. (2019). Characterization and engineering properties of the NGTS Onsøy soft clay site. AIMS Geosci. 5, No. 3, 665-703.

Han, D. H. \& Batzle, M. L. (2004). Gassmann's equation and fluid-saturation effects on seismic velocities. Geophysics $\mathbf{6 9}$, No. 2, 398-405.

Han, D. H., Nur, A. \& Morgan, D. (1986). Effects of porosity and clay content on wave velocities in sandstones. Geophysics 51, No. 11, 2093-2107.

Hart, D. J. \& Wang, H. F. (1995). Laboratory measurements of a complete set of poroelastic moduli for Berea sandstone and Indiana limestone. J. Geophys. Res.: Solid Earth 100, No. B9, 17741-17751.

Hart, D. J. \& Wang, H. F. (2010). Variation of unjacketed pore compressibility using Gassmann's equation and an overdetermined set of volumetric poroelastic measurements. Geophysics 75, No. 1, N9-N18.

Hauck, C., Böttcher, M. \& Maurer, H. (2011). A new model for estimating subsurface ice content based on combined electrical and seismic data sets. The Cryosphere 5, No. 2, 453-468.

Helgerud, M. B., Dvorkin, J., Nur, A., Sakai, A. \& Collett, T. (1999). Elastic-wave velocity in marine sediments with gas hydrates: effective medium modeling. Geophys. Res. Lett. 26, No. 13, 2021-2024.

Hill, R. (1952). The elastic behaviour of a crystalline aggregate. Proc. Phys. Soc. London, Sect. A 65, No. 5, 349.

Hivon, E. \& Sego, D. (1995). Strength of frozen saline soils. Can. Geotech. J. 32, No. 2, 336-354.

Katahara, K. W. (1996). Clay mineral elastic properties. In $S E G$ technical program expanded abstracts 1996, pp. 1691-1694. Tulsa, OK, USA: Society of Exploration Geophysicists.

Kia, M. (2012). Measuring pore-water pressure in partially frozen soils. DPhil thesis, University of Alberta, Edmonton, Alberta, Canada.

King, M. (1984). The influence of clay-sized particles on seismic velocity for Canadian Arctic permafrost. Can. J. Earth Sci. 21, No. 1, 19-24.

King, M. S., Zimmerman, R. W. \& Corwin, R. F. (1988). Seismic and electrical-properties of unconsolidated permafrost. Geophys. Prospect. 36, No. 4, 349-364.

Kneisel, C., Hauck, C., Fortier, R. \& Moorman, B. (2008). Advances in geophysical methods for permafrost investigations. Permafr. Periglac. Processes 19, No. 2, 157-178.
Kuster, G. T. \& Toksöz, M. N. (1974). Velocity and attenuation of seismic waves in two-phase media: part I. Theoretical formulations. Geophysics 39, No. 5, 587-606.

Leclaire, P., Cohen-Ténoudji, F. \& Aguirre-Puente, J. (1994). Extension of Biot's theory of wave propagation to frozen porous media. J. Acoust. Soc. Am. 96, No. 6, 3753-3768.

Lee, M. W. (2002). Biot-Gassmann theory for velocities of gas hydrate-bearing sediments. Geophysics 67, No. 6, 1711-1719.

Lee, J. S. \& Santamarina, J. C. (2005). Bender elements: performance and signal interpretation. J. Geotech. Geoenviron. Engng 131, No. 9, 1063-1070.

Lee, M. W., Hutchinson, D. R., Collett, T. S. \& Dillon, W. P. (1996). Seismic velocities for hydrate-bearing sediments using weighted equation. J. Geophys. Res.: Solid Earth 101, No. B9, 20347-20358.

Liu, J., Yang, P. \& Yang, Z. J. (2020). Electrical properties of frozen saline clay and their relationship with unfrozen water content. Cold Reg. Sci. Technol. 178, 103127.

Lyu, C., Ghoreishian Amiri, S. A., Grimstad, G., Høyland, K. V. \& Ingeman-Nielsen, T. (2020). Comparison of geo-acoustic models for unfrozen water content estimation. J. Geophys. Res.: Solid Earth 125, No. 10, e2020JB019766.

Makhnenko, R. Y. \& Labuz, J. F. (2016). Elastic and inelastic deformation of fluid-saturated rock. Phil. Trans. R. Soc. A: Math., Phys. Engng Sci. 374, No. 2078, 20150422.

Mesri, G., Adachi, G. \& Ullrich, C. (1976). Pore-pressure response in rock to undrained change in all-round stress Géotechnique 26, No. 2, 317-330, https://doi.org/10.1680/geot. 1976.26.2.317.

Patterson, D. \& Smith, M. (1985). Unfrozen water content in saline soils: results using time-domain reflectometry. Can. Geotech. J. 22, No. 1, 95-101.

Patton, A. I., Rathburn, S. L. \& Capps, D. M. (2019). Landslide response to climate change in permafrost regions. Geomorphology 340, 116-128.

Romero, E. \& Simms, P. H. (2008). Microstructure investigation in unsaturated soils: a review with special attention to contribution of mercury intrusion porosimetry and environmental scanning electron microscopy. Geotech. Geol. Engng 26, No. 6, 705-727.

Romero, E., Gens, A. \& Lloret, A. (1999). Water permeability, water retention and microstructure of unsaturated compacted Boom clay. Engng Geol. 54, No. 1-2, 117-127.

Skempton, A. (1954). The pore-pressure coefficients $A$ and $B$. Géotechnique 4, No. 4, 143-147, https://doi.org/10.1680/geot. 1954.4.4.143.

Smith, T. M., Sondergeld, C. H. \& Rai, C. S. (2003). Gassmann fluid substitutions: a tutorial. Geophysics 68, No. 2, 430-440.

Vanorio, T., Prasad, M. \& Nur, A. (2003). Elastic properties of dry clay mineral aggregates, suspensions and sandstones. Geophys. J. Int. 155, No. 1, 319-326.

Vaughan, M. J., Wijk, K. V., Prior, D. J. \& Bowman, M. H. (2016) Monitoring the temperature-dependent elastic and anelastic properties in isotropic polycrystalline ice using resonant ultrasound spectroscopy. The Cryosphere 10, No. 6, 2821-2829.

Vogt, C., Laihem, K. \& Wiebusch, C. (2008). Speed of sound in bubble-free ice. J. Acoust. Soc. Am. 124, No. 6, 3613-3618.

Wang, Z. J., Wang, H. \& Cates, M. E. (2001). Effective elastic properties of solid clays. Geophysics 66, No. 2, 428-440.

Yun, T. S., Santamarina, J. C. \& Ruppel, C. (2007). Mechanical properties of sand, silt, and clay containing tetrahydrofuran hydrate. J. Geophys. Res.: Solid Earth 112, No. B4, B04106, https://doi.org/10.1029/2006JB004484.

Zhou, J., Meng, X., Wei, C. \& Pei, W. (2020). Unified soil freezing characteristic for variably-saturated saline soils. Water Resour. Res. 56, No. 7, e2019WR026648.

Zimmerman, R. W. \& King, M. S. (1986). The effect of the extent of freezing on seismic velocities in unconsolidated permafrost. Geophysics 51, No. 6, 1285-1290. 